\title{
Nerve-dependent Modulation of Acetylcholine Receptor $\epsilon$-Subunit Gene Expression
}

\author{
Jean-Claude Martinou and John Paul Merlie \\ Department of Molecular Biology and Pharmacology, Washington University Medical School, St. Louis, Missouri 63110
}

\begin{abstract}
The relative abundance of mRNAs encoding the $\gamma$ - and $\epsilon$-subunits of acetylcholine receptor changes in opposite directions during mouse development. Both $\gamma$ - and $\epsilon$-mRNAs are expressed early in muscle development in vivo, and in aneural embryonic muscle and myogenic cell lines in vitro, though $\gamma$-mRNA is at least 20 -fold more abundant than $\epsilon$-mRNA in these circumstances. While during normal development, $\gamma$-mRNA decreases to an undetectable level by postnatal day 12, $\epsilon$-mRNA first increases 10 -fold between day 2 and day 12-15, then decreases to the level characteristic of adult muscle. We have found that the transition form $\gamma$ - to $\epsilon$-mRNA is influenced by the levels of thyroid hormones. Indeed, high and low levels of thyroid hormones, respectively, accelerated and delayed the switch between $\gamma$ - and $\epsilon$-mRNAs. Neither the dramatic postnatal rise in e-mRNA nor its sensitivity to thyroid hormones was observed in denervated newborn animals. By contrast, denervation was without effect on $\epsilon$-mRNA expression in adult muscle. These results suggest that, although not required for the initial activation of the $\epsilon$-gene nor its maintenance in adult muscle, the nerve plays a major role in the perinatal regulation of $\epsilon$-gene transcription.
\end{abstract}

During the maturation of the neuromuscular junction, the electrophysiological properties of the nicotinic acetylcholine receptor $(\mathrm{AChR})$ channels are progressively modified. Embryonic muscles express AChR channels with long open time and low conductance (slow channels), whereas adult muscles express AChR with short open time and high conductance (fast channels) (Sakmann and Brenner, 1978; Schuetze et al., 1978; Fischbach and Schuetze, 1980; Kullberg et al., 1981; Brehm et al., 1984). Several hypotheses have been proposed to explain the molecular basis for this change in channel function (Fischbach and Schuetze, 1980; Brenner and Sakmann, 1983; Brenner, 1985). Recently, Mishina et al. (1986) demonstrated that a change in the subunit complement of the pentameric receptor can account for changes in channel properties. When bovine AChR was

\footnotetext{
Received Sep. 5, 1990; revised Dec. 4, 1990; accepted Dec. 7, 1990.

We thank Despina Ghement for technical assistance; A. Lassar for providing cell lines 10T $1 \frac{1}{2}$ and F3; Mike Crowder and Don Frail for technical advice; and Bill Phillips, Cathy Prody, and David McKinnon for reading the manuscript. Research was supported by funds from the Senator Jacob Javits Center of Excellence in the Neurosciences and by research grants to J.P.M. from the Nationa Institutes of Health and the Muscular Dystrophy Association of America.

Correspondence should be addressed to J. P. Merlie, Department of Pharmacology, Box 8103, Washington University Medical School, 660 S. Euclid Avenue St. Louis, MO 63110.

a Present address: Département de Pharmacologie, Université de Geneve, Geneva, Switzerland.

Copyright (C) 1991 Society for Neuroscience $0270-6474 / 91 / 111291-09 \$ 03.00 / 0$
}

expressed in Xenopus oocytes, the replacement of $\gamma$ subunit by a recently discovered $\epsilon$ subunit (Takai et al., 1985) resulted in characteristic fast channels. In addition, a change from $\gamma$ - to $\epsilon$-mRNA (Mishina et al., 1986; Witzemann et al., 1989) and $\gamma$ to $\epsilon$-antigenic determinants (Gu and Hall, 1988) occurs at approximately the same stage of muscle development as the alteration in channels properties. These findings suggest that the switch from $\gamma$ - to $\epsilon$-subunit is responsible, at least in part, for the functional alteration of the receptor during the maturation of the neuromuscular junction.

Although the factors that govern the switch between $\gamma$ - and $\epsilon$-subunits are unknown, the role of the nerve has been the focus of investigation. In large part, observations have conflicted, due apparently to differences between species. In Xenopus, neither innervation (Brehm et al., 1982; Leonard et al., 1984; Brehm et al., 1984; Igusa and Kidokoro, 1987) nor muscle activity (Kullberg et al., 1985) are required for the expression of fast channels. On the contrary, in rat, the nerve seems to be essential for the postnatal development of fast channels. Schuetze and Vicini (1984), using noise analysis methods, found that denervation of neonatal rat soleus muscle prevents, or delays, the appearance of fast channels. These results suggest that, whereas in Xenopus the expression of AChR of the fast channel type is regulated primarily by factors intrinsic to the myogenic program, in rat $\epsilon$-subunit regulation depends significantly on extrinsic influences. Nerve-evoked activity and/or trophic molecules released by motor neurons are suggested mediators of these extrinsic effects (Brenner and Sakmann, 1983; Brenner et al., $1983,1987)$. In view of these results, we have investigated the changes in $\gamma$ - and $\epsilon$-subunit mRNAs during normal mouse development, in response to denervation, and in response to perturbations in the perinatal levels of thyroid hormone. We have found that a low level of $\epsilon$-gene transcription occurs as a normal part of the intrinsic myogenic program in cell lines and primary cultures of embryonic skeletal muscle cells. However, a dramatic postnatal increase, peaking on day $12-15$, in $\epsilon$-mRNA expression depends on the presence of motor nerve.

\section{Materials and Methods}

Mice. Outbred ND4 Swiss Webster or ICR mice from Harlan SpragueDawley (Indianapolis, IN) were used for all experiments. Newborn mice were denervated at PN4 under cold anesthesia by removal of a fragment of the sciatic nerve of a single leg. Four and eight days later, the gastrocnemius muscle was carefully dissected under the microscope after verifying that the denervation had been successful. Newborn mice were made hypothyroid by treating their mothers, from the last 7 days of gestation, with propylthiouracil (PTU; Sigma, St. Louis, MO) $0.1 \%$ in their drinking water and a low iodine diet (Purina Mills Inc., St. Louis, MO). Hyperthyroidism was induced with a daily subcutaneous injection of $5 \mu \mathrm{g}$ of thyroxine (Sigma). Serum thyroxine levels were measured by a radioimmunoassay (Biorad, Richmond, CA). 

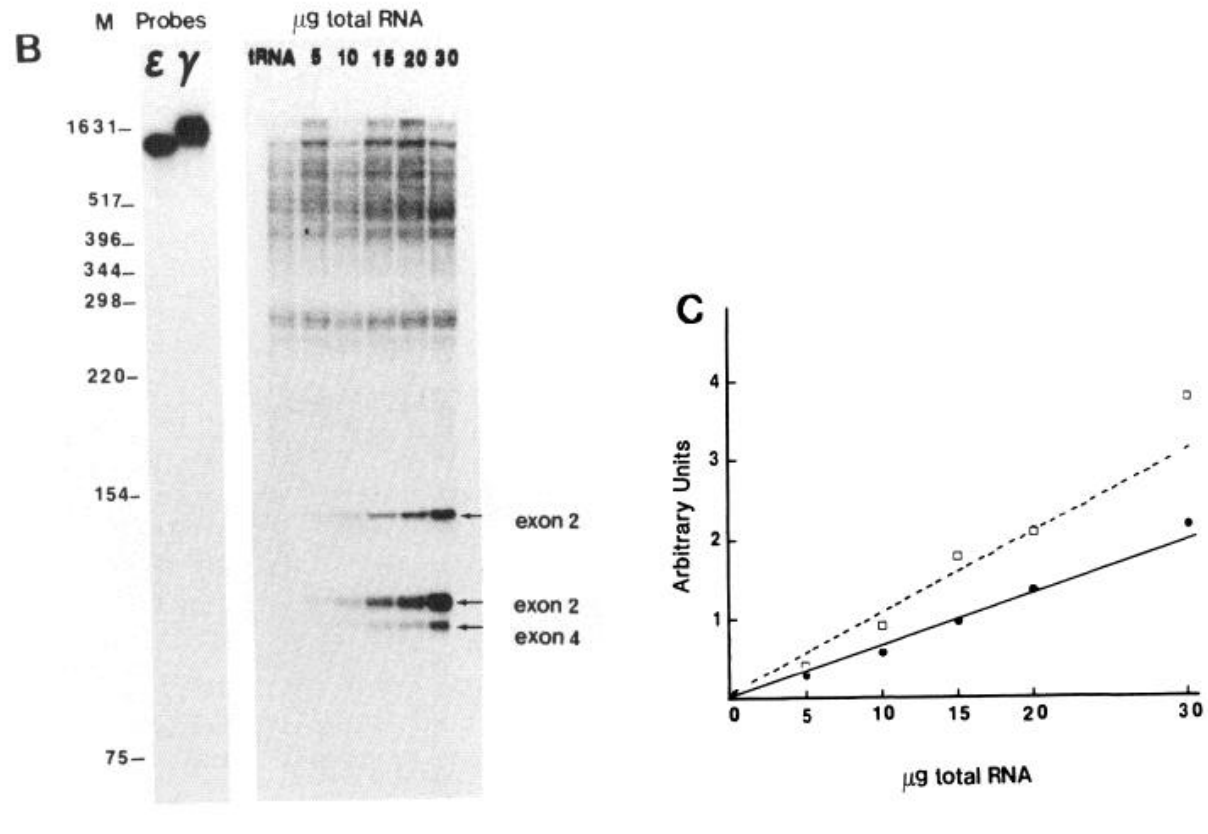

Figure 1. Detection and quantitation of mouse muscle $\gamma$ - and $\epsilon$-mRNA by RNAse protection. $A$, Map of the $\gamma$-and $\epsilon$-genomic DNA fragments used to generate the probes for RNAse protections. $H$, HindIII restriction site. $B$, Different concentrations $(5-30 \mu \mathrm{g})$ of total RNA from 4-d-old mouse muscle containing both $\gamma$ - and $\epsilon$-transcripts were assayed by RNAse protection with both $\gamma$ - and $\epsilon$-probes. $C$, The protected bands corresponding to exons 2 for both $\gamma$ - and $\epsilon$-mRNA were quantitated and the results from scanning densitometry represented in the graph after normalization for specific activity. $\gamma$-mRNA, $\square----\square ; \epsilon$-mRNA,
A

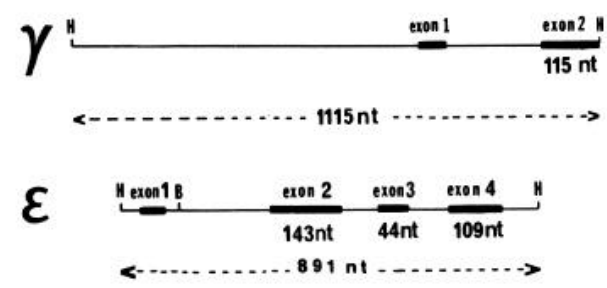

was washed twice in $70 \%$ ethanol, dried, and analyzed on $7.5 \%$ polyacrylamide, $7 \mathrm{~m}$ urea gels. Gels were dried and exposed to Kodak XAR film with intensifying screen.

Cell cultures. The different clonal cell lines, BC3H-1 (Schubert et al., 1974), F3 (Lassar et al., 1986), and C2 (Yaffe and Saxel, 1977) were grown as detailed elsewhere (Crowder and Merlie, 1986; Frail et al., 1989). Muscle primary cultures were prepared from E17-19 limb muscles. Minced muscles were incubated $1 \mathrm{hr}$ at $37^{\circ} \mathrm{C}$ in a solution of $0.25 \%$ trypsin, $0.05 \%$ DNAase I in Hank's balanced salt solution without $\mathrm{Ca}^{2+}$, $\mathrm{Mg}^{2+}$. Following trypsination, cells were centrifuged $10 \mathrm{~min}$ at 2000 $\mathrm{rpm}$, resuspended in the culture medium: DME, $10 \%$ horse serum, $5 \%$ newborn calf serum, filtered through $150-\mu \mathrm{m}$ Nitex filters and plated at a density of $7 \times 10^{6}$ cells per 6 -cm collagenized plate.

\section{Results}

\section{Quantitation of $\gamma$ - and $\epsilon-m R N A$ by RNAase protection}

To study the regulation of $\gamma$ - and $\epsilon$-mRNA in vivo and in vitro, we used the RNAase protection method (Melton et al., 1984). Each RNA preparation was hybridized concomitantly, in the same tube, with both $\gamma$ - and $\epsilon$-probes. The $\gamma$-probe was made with a $1.1 \mathrm{~Kb}$ HindIII fragment of the mouse $\gamma$-gene and contained exons 1 and 2 . Only the band protected by exon 2 (115 bp) has been quantitated (Fig. 1). The $\epsilon$-probe contained exons 2, 3, and 4. Only exon 2 (143 bp) and exon 4 (109) are present on the gel shown in Figure 1. For each experiment, autoradiographic bands corresponding to exons 2 of both $\gamma$ - and $\epsilon$-mRNA were scanned and the densitometric results were normalized to the specific activity of the probes. This enabled a comparison of the relative proportion of both RNA species in each sample. As $\gamma$ - and $\epsilon$-mRNA levels change in an inverse fashion during 
A

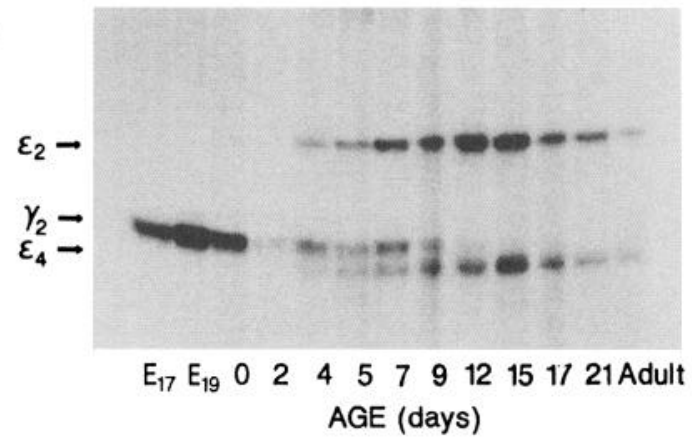

B

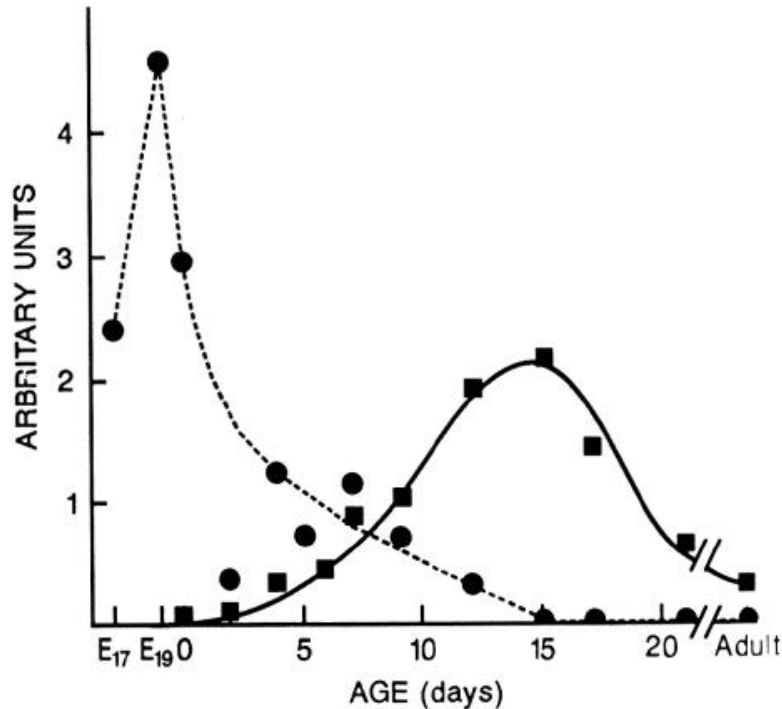

Figure 2. Alterations in the levels of $\gamma$ - and $\epsilon$-mRNA during development in mouse muscle. Total RNA (25 $\mu \mathrm{g})$ was prepared from lower leg muscles of mice at different stages of development. $A, \gamma$ - and $\epsilon$-mRNA levels were measured by RNAase protection. Each point was obtained with RNA prepared from 1-3 litters of mice (average 10-12 mice/litter). $B$, The data in the graph were obtained by scanning densitometry and were normalized for specific activity $(\gamma$-mRNA, --- $\epsilon$-mRNA, $\square$. This experiment has been repeated three times with consistent results.

development (see below), the presence of both probes in each sample constituted a good control for the integrity of individual RNA samples. In addition, RNA integrity was monitored by Northern blot analysis of actin mRNA. For calibration, different concentrations $(5-30 \mu \mathrm{g})$ of a sample containing comparable amounts of both $\gamma$ - and $\epsilon$-mRNA were assayed. The result presented in Figure 1 shows that the intensities of the $115 \mathrm{bp} \gamma$ and $143 \mathrm{bp} \epsilon$-protected fragments increase linearly with the concentration of RNA. In addition, the ratio between $\epsilon-$ and $\gamma$-values remains constant with the different concentrations of total RNA. Thus, this technique is suitable for quantitative analysis of $\gamma$ - and $\epsilon$-mRNAs in the concentration range required for our study.

\section{Alterations in the levels of $\gamma$ - and $\epsilon-m R N A$ during development in mouse muscle}

The levels of $\gamma$ - and $\epsilon$-subunit mRNAs have been measured by RNAase protection in total RNA prepared from the gastrocnemius muscles of embryonic (E) or postnatal (PN) mice (Fig. 2 ). We found that $\gamma$ - and $\epsilon$-mRNA levels change in an opposite fashion during the first 2 postnatal weeks; $\gamma$-mRNA increased from E17 to a maximum at E19, then decreased to an undetectable level after day PN12. Conversely, the increase of $\epsilon$-mRNA levels occurred postnatally. $\epsilon$-mRNA was detectable at a low level in E19 muscles, increased about 10-fold between PN2 and PN15, then decreased in older mice to reach a level comparable to PN4. The peak of $\gamma$-mRNA at E19 was approximately 2-fold higher than the peak of $\epsilon-\mathrm{mRNA}$ at PN15. Between PN5 and PN7, muscles contained approximately equal quantities of $\gamma$ - and $\epsilon$-mRNA, and in adult mice the level of $\epsilon$-mRNA was approximately 25 -fold that of $\gamma$-mRNA.

\section{Expression of $\gamma$ - and $\epsilon-m R N A$ in clonal cell lines and} primary cultures of embryonic muscle

To determine whether innervation is necessary for the initial activation of the $\epsilon$-gene, we investigated whether aneural muscle cultures expressed $\epsilon$-mRNA. For this purpose, muscle primary cultures from E17-19 mouse embryos and also the different clonal mouse cell lines $\mathrm{F} 3, \mathrm{C} 2$, and $\mathrm{BC} 3 \mathrm{H}-1$ were assayed for the presence of $\epsilon$-mRNA (Fig. 3). We found that all cultures expressed $\epsilon$-mRNA 2-5 d after myotube formation or after cell differentiation in the case of $\mathrm{BC} 3 \mathrm{H}-1$. The percentage of $\epsilon-$ relative to $\gamma$-mRNA for each culture is shown in Figure 3. In all cases, $\epsilon$-mRNA accounted for only $1 \%$ to $5 \%$ of the total amount of $\gamma$-mRNA $+\epsilon$-mRNA. Older cultures did not express higher proportions of $\epsilon-m R N A$ (data not shown).

Although these cultures were prepared in the absence of nerve, or extracts of neural tissue, it could be argued that the $\epsilon$-gene was already induced by innervation before the muscles were removed for culture. However, the fact that $\mathrm{BC} 3 \mathrm{H}-1$, a cell line derived from the cranial neoplasm (Schubert et al., 1974), expresses $\epsilon$-mRNA suggests that the nerve is not required for the initial induction of the $\epsilon$-gene. Furthermore, the expression of $\epsilon$-mRNA in F3, a muscle cell line induced in vitro from a line of embryonic fibroblasts (10T $1 / 2)$ with 5-azacytidine (Taylor and Jones, 1979; Lassar et al., 1986), suggests that the initial expression of $\epsilon$, as for the other AChR subunits, depends in large part on an intrinsic program of myogenesis.

\section{Role of thyroid hormones in the development of $\gamma$ - and $\epsilon-m R N A$}

Measurements of serum thyroxine levels have shown that the mouse is "hypothyroid" at birth, becomes transiently "hyperthyroid" at PN15, and finally reaches a mature, euthyroid state between PN15-PN21 (Fig. 4). Comparable results have been obtained in rats (Gambke et al., 1983; Chizzonite and Zak, 1984). The similarity between the time-course of development of $\epsilon$-mRNA and the serum levels of thyroxine prompted us to study the role of thyroid hormones in the regulation of the switch from $\gamma$ - to $\epsilon$-subunit expression. Also in support of this hypothesis, Kawa and Obata (1982) have shown that miniature end-plate potential (m.e.p.p.) duration (an indicator of channel open time distribution) was affected by the levels of thyroid hormones. 
Figure 3. Expression of $\gamma-$ and $\epsilon$-mRNA in clonal cell lines and primary cultures of embryonic muscle. The presence of $\gamma$ - and $\epsilon$-mRNA has been assayed in P.C. Primary Cultures; $B C 3 H-1$ cells; $F 3$ cells; and $C 2$ cells. The levels of $\gamma$ - and $\epsilon$-mRNA measured by RNAase protection 2-5 d after myotube formation or cell differentiation are expressed as percentage of the total amount of $\gamma$-mRNA $+\epsilon$-mRNA. The relevant regions of the autoradiograms are shown.

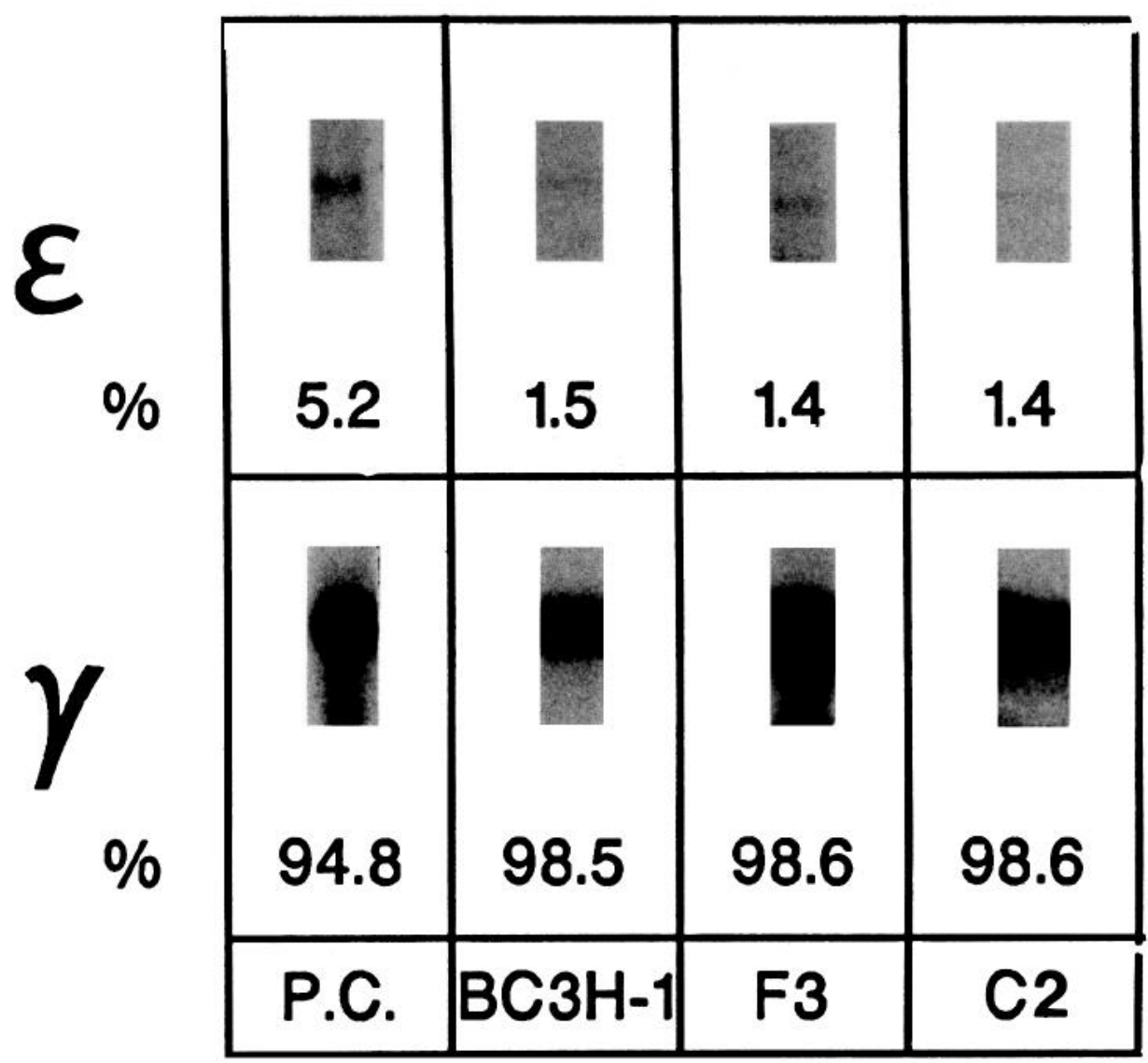

For the purpose of assessing the role of thyroid hormone, mice were made hypothyroid by administration of PTU or hyperthyroid with thyroxine (see Materials and Methods). Figure 4 shows that in PTU-treated animals, serum thyroxine was below detectable levels. In thyroxine-injected animals, the serum levels were always at least 3 -fold above normal untreated animals.

The content of $\gamma$ - and $\epsilon$-mRNA have been compared in lower leg muscles of hypothyroid, euthyroid, and hyperthyroid mice. In PTU-treated mice, the disappearance of $\gamma$-mRNA was markedly retarded. At PN4, the level of $\gamma$-mRNA was 2-fold higher than in normal mice of the same age (Fig. 5). This difference increased to 3.5-fold at PN7, and $\gamma$-mRNA was still detectable at PN16, disappearing between PN16 and PN21 (Fig. 6A). The development of $\epsilon$-mRNA was also altered in these mice. At PN4, the level was 3.5-fold lower in hypo- than in euthyroid mice (Fig. 5), and the dramatic rise and decline of $\epsilon$-mRNA normally observed did not occur (Figs. 5, 6A). The level of $\epsilon$-mRNA at PN21 was not significantly different from the levels at PN7 or PN9.

Opposite effects were observed in hyperthyroid mice (Figs. 5, $6 B)$. At PN4 and PN7 the levels of $\gamma$-mRNA were 2 -fold lower than in control mice (Fig. 5). The disappearance of $\gamma$-mRNA was thus accelerated 1-2 days. In 4 of 6 different groups of thyroxine-treated mice, $\gamma$-mRNA was not detectable at PN9 whereas it was always present in the control animals. The development of $\epsilon$-mRNA was accelerated as the peak of expression was reached at PN7, i.e., 5-8 days before the normal peak. The levels of $\epsilon$-RNA then declined to normal at PN21. Thus, thyroid hormone stimulated the development of $\epsilon-\mathrm{mRNA}$ during the first 15 postnatal days but did not prevent the decrease observed in older animals.

The effects of injected thyroid hormones were observed until the mice reached an euthyroid status. Injections of thyroxine after PN8 had no effect on the expression of $\epsilon$-mRNA (data not shown).

\section{Effects of denervation on $\gamma$ - and $\epsilon$-subunit mRNA levels}

Newborn mice were denervated at day PN4 and the levels of $\gamma$ - and $\epsilon$-mRNA measured at PN8 and PN12. We found that, in the absence of the nerve, the increase in $\epsilon$-subunit mRNA did not occur. Indeed, Figure $7 A$ and Table 1 show that the levels of $\epsilon$-mRNA observed at PN8 and PN12 denervated muscles are not different from those observed at PN4. On the other hand, denervation resulted in a dramatic increase in the level of $\gamma$-mRNA.

In order to determine whether the effects of thyroid hormones were mediated via the nerve, rather than directly on the muscle, denervation experiments were performed on hyperthyroid mice. We observed that in the absence of the nerve the effects of high levels of thyroxine on the development of both $\gamma$ - and $\epsilon$-subunit mRNA were suppressed (Fig. 7B). Indeed, as in untreated denervated animals, the level of $\epsilon$-mRNA did not increase between PN4 and PN12. In contrast, in control muscles, thyroxine was effective because the level of $\epsilon$-mRNA was higher at PN8 than at PN12. This level was also 2-fold higher than the level measured in muscles of untreated animals at the same age. Thus, the effects of thyroxine on the increase of $\epsilon$-mRNA or disappearance of $\gamma$-mRNA appear to be mediated indirectly via the nerve. In support of this conclusion, we have found that thy- 


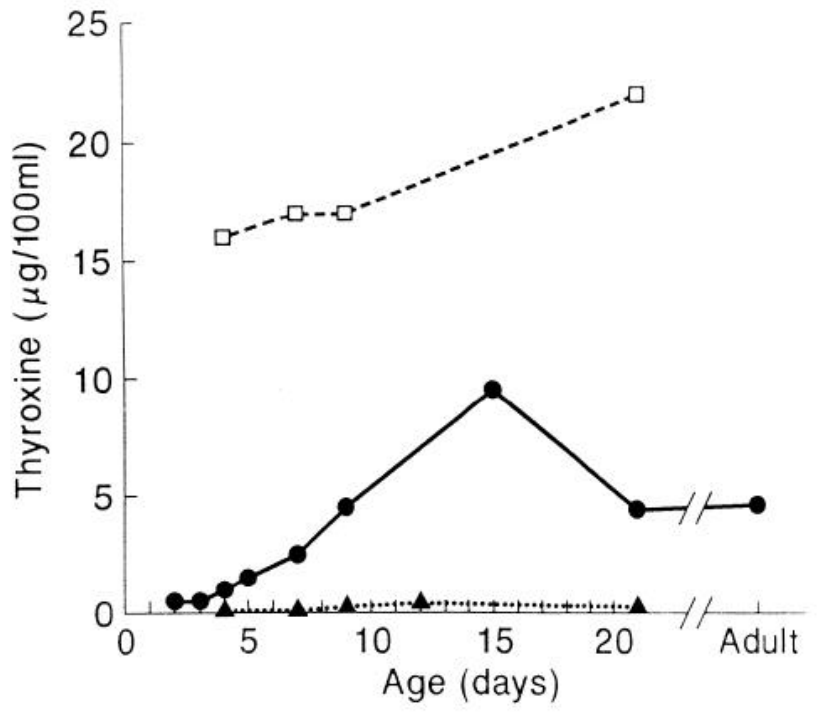

Figure 4. Serum T4 levels of normal, hypo- and hyperthyroid mice during development. Serum T4 levels were measured by RIA in normal animals (-), in PTU-treated animals $(\boldsymbol{\Lambda}-\mathbf{\Delta})$ and in mice having received a daily injection of $T 4(\square-\cdots--\square)$. Data are expressed as $\mu \mathrm{g} \mathrm{T} 4$ per $100 \mathrm{ml}$ serum.

roxine treatment of aneural primary muscle cells in tissue culture is without effect on $\gamma$ - or $\epsilon$-mRNA levels (J.-C. Martinou, D. L. Falls, G. D. Fischbach, and J. P. Merlie, unpublished observations).

To determine whether muscle activity was responsible for the low level of expression of $\epsilon$-mRNA in adult muscle, we analyzed the effect of denervation in adult gastrocnemius and soleus muscles (Fig. 8). We found that the levels of $\epsilon$-mRNA measured 4 and $8 \mathrm{~d}$ after denervation did not change and were not significantly different from control levels. In contrast $\gamma$-mRNA levels, not detected in control muscles, were reexpressed at a high level in denervated muscles. These results are consistent with earlier results of Witzemann et al. (1987), and show that the continued expression of $\epsilon$-mRNA in adult muscle fibers is independent of nerve.

\section{Discussion}

During amphibian and mammalian muscle development, the electrophysiological properties of the AChR change from an embryonic long open time low conductance channel to an adult short open time high conductance channel (Sakmann and Brenner, 1978; Fischbach and Schuetze, 1980; Michler and Sakmann, 1980; Kullberg et al., 1981, 1985; Brehm et al., 1984). The data of Mishina et al. (1986), Witzemann et al. (1989), and $\mathrm{Gu}$ and Hall (1988) provide convincing evidence that the change in channel properties results, at least in part, from the replacement of $\gamma$ - by $\epsilon$-subunit in the pentameric receptor. The regulation of the switch from $\gamma$ - to $\epsilon$-expression is far from understood. In particular, the factors that govern the expression of the $\epsilon$-gene are unknown. Here, we report a study on the regulation of expression of $\gamma$ - and $\epsilon$-mRNA in mouse. In agreement with electrophysiological studies in Xenopus (Brehm et al., 1982; Greenberg et al., 1985; Leonard et al., 1988) and rat (Siegelbaum et al., 1984) embryonic muscle cell cultures, we have shown that the nerve is not required for initial expression of the $\epsilon$-gene at low levels. This is most clearly demonstrated in the case of
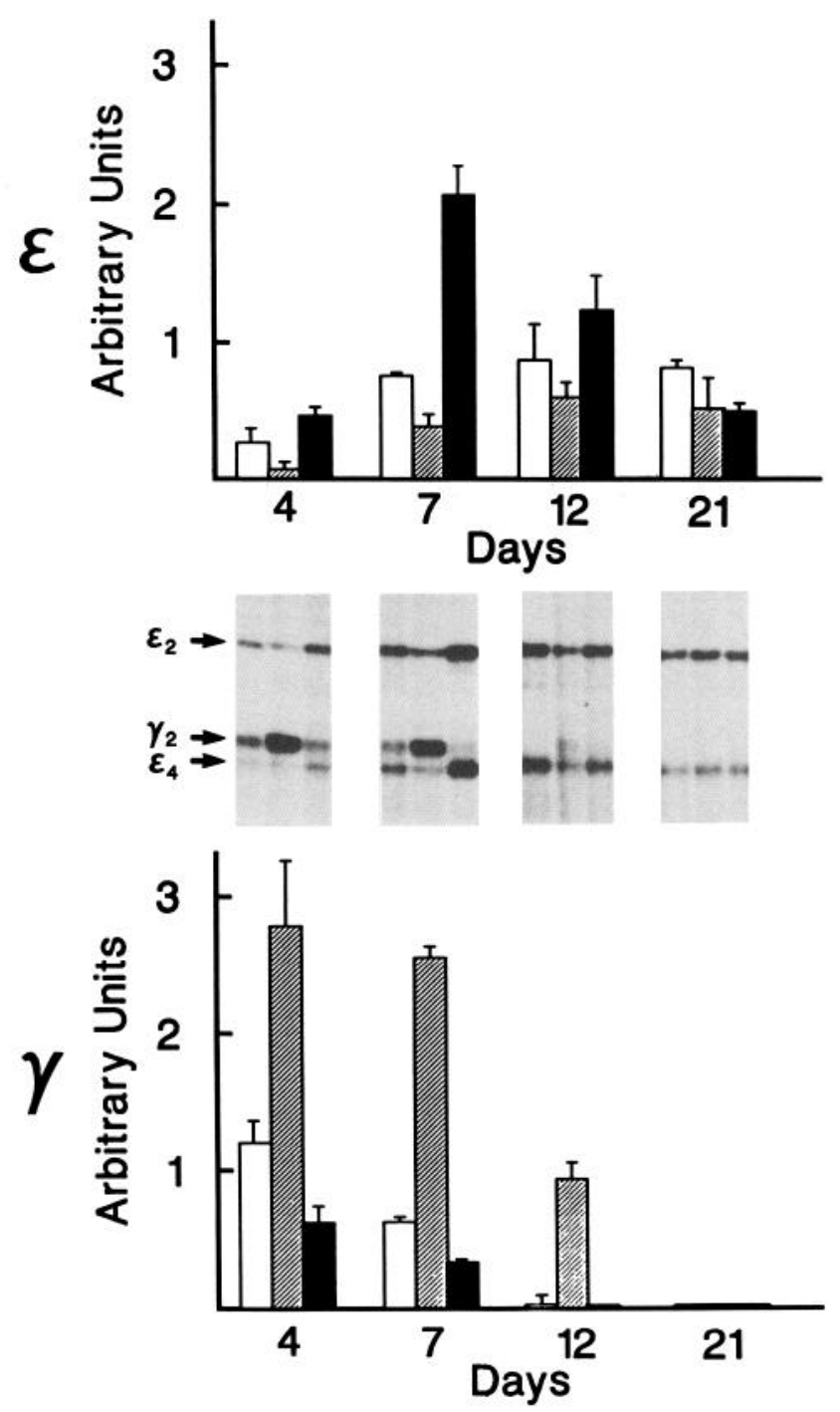

Figure 5. Comparison of $\gamma$ - and $\epsilon$-mRNA in eu-, hypo-, and hyperthyroid mice. The levels of $\gamma$ - and $\epsilon$-mRNA have been measured in total RNA from lower leg muscles of eu- ( $\square$ ), hypo- (ש), and hyperthyroid (घ) (see Materials and Methods) at different stages of the development. The histograms are mean \pm SEM of three different samples. The inset between the bar graphs shows a photograph of the autoradiograms from which the data were obtained.

the F3 cell line, derived in vitro by 5 -azacytidine treatment of the stem cell-like line, C3H10T $1 / 2$ (Taylor and Jones, 1979). Furthermore, in all muscle cell lines examined, $\alpha-, \beta-, \gamma-$, and $\delta$-subunit mRNAs are expressed at maximal levels. The endogenous myogenic program in mouse, therefore, results in acti-

Table 1. Effects of denervation on $\gamma$ - and $\epsilon$-mRNA expression in newborn mice

\begin{tabular}{lccl} 
& Day 4 & Day 12 & \\
\cline { 3 - 4 } & & Innervated & Denervated \\
\hline$\gamma$-mRNA & 100 & $15 \pm 5$ & $352 \pm 29$ \\
$\epsilon$-mRNA & 100 & $342 \pm 125$ & $111 \pm 12$
\end{tabular}

This table summarizes the results obtained from three different experiments similar to the one described in the legend of Figure 7. Results have been normalized to total RNA. Data are expressed as percentages of those obtained at day 4 and are means \pm SEM. 


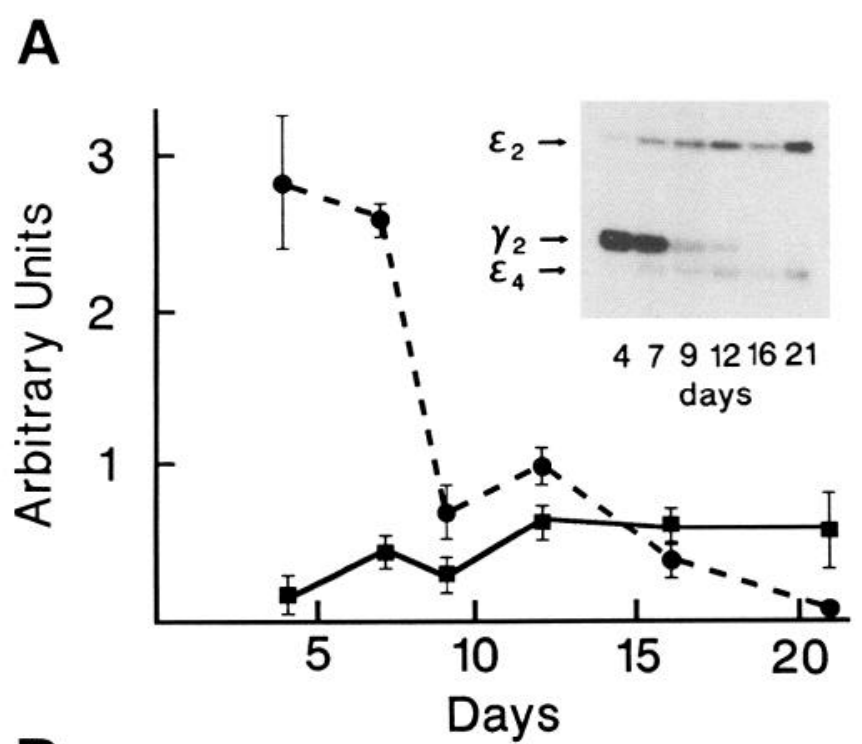

B

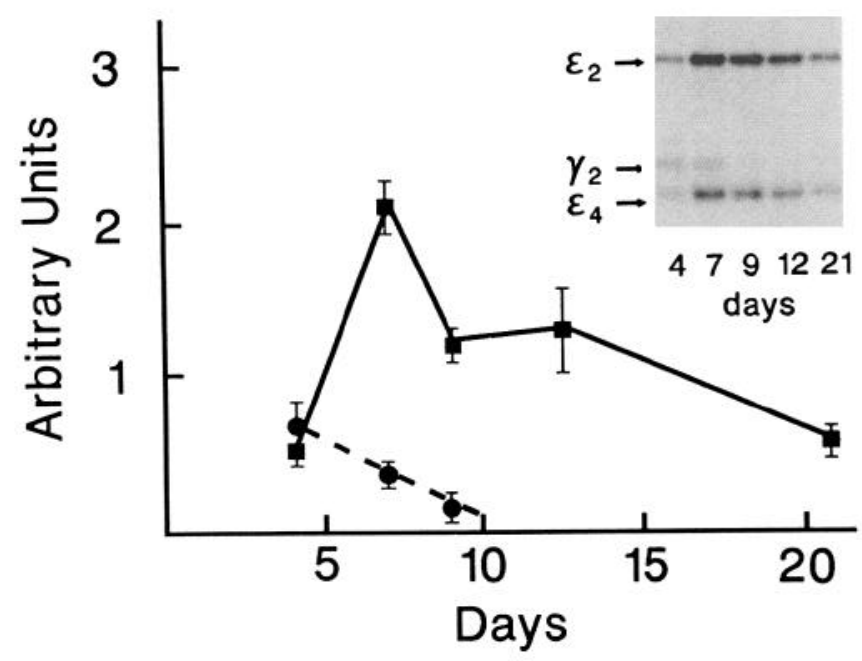

Figure 6. Development of $\gamma$ - and $\epsilon$-mRNA in hypothyroid and hyperthyroid mice. $A$, Mice were made hypothyroid with PTU or $B$, hyperthyroid with a daily injection of $5 \mu \mathrm{g}$ of T 4 (see Materials and Methods). RNA was assayed for the presence of $\gamma\left(\bullet_{-\cdots}-\cdots\right)$ and $\epsilon(\square-\square)$ mRNA. The results reported at each day (4-7-9-12-16-21) correspond to the mean + SEM of three different samples. Each sample corresponds to RNA from 3-12 mice. The insets show the photographs of autoradiograms from which the data were obtained.

vation of all 5 muscle $\mathrm{AChR}$ genes, $\alpha, \beta, \gamma$, and $\delta$ at high levels and $\epsilon$ at a low level. This pattern of expression of AChR subunits adequately accounts for the abundance of fast type versus slow channels observed in embryonic rat muscle cells (Siegelbaum et al., 1984).

Shortly after birth, as shown here for the mouse and previously for the rat (Witzemann et al., 1989), a reciprocal change in $\gamma$ - and $\epsilon$-mRNA levels occurs. By day $12-15, \gamma$-mRNA is no longer detectable, whereas $\epsilon$-mRNA is expressed at a maximum level. Consistent with results of earlier electrophysiological studies on the role of thyroid hormones in the maturation of the neuromuscular junction in newborn rats (Kawa and Obata, 1982), we found that thyroid hormones accelerated the switch from $\gamma$ to $\epsilon$-subunit mRNA. However, neither the dramatic postnatal rise in $\epsilon$-mRNA nor its sensitivity to thyroid hormones were observed in denervated newborn animals, suggesting that $\epsilon$-mRNA modulation is mediated by the motor nerve. The latter findings are contradictory to recent results obtained by Northern blot analysis (Witzemann et al., 1989) and in situ hybridization (Brenner et al., 1990) showing that the postnatal accumulation of $\epsilon$-mRNA in rat does not require the continued presence of the nerve. Although differences in the experimental procedures may explain the discrepancy between our results and those of Witzemann et al. (1989) and Brenner et al. (1990), we believe that the most likely explanation is that $\epsilon$-gene expression becomes independent of the nerve earlier in the rat than in the mouse. In both adult rats and mice, $\epsilon$-mRNA levels are independent of changes caused by denervation. In rat, this "imprinting" phenomenon has occurred before PN1; in mouse, imprinting occurs after PN4.

Recently, we have found that ARIA, a glycoprotein purified from chick brain and spinal cord, stimulates the level of $\epsilon$-mRNA up to 10-fold in primary cultures of mouse muscle cells. The effect was specific in that $\alpha-, \gamma-$, and $\delta$-mRNA levels were stimulated only 2 -fold or less and $\beta$-mRNA not at all. These effects of ARIA were independent of muscle activity and not common to other putative neurotrophic effectors (Martinou, Falls, Fischbach, and Merlie, unpublished observations). Thus, ARIA is a good candidate for a nerve-derived signal that may initiate the stable postnatal increase in $\epsilon$-mRNA.expression.

After postnatal day 15 the relative abundance of $\epsilon$-mRNA decreases approximately 5 -fold to a low steady state level. Although this decrease occurs at approximately the same time as the decreases in mRNA levels for $\alpha, \beta, \gamma$, and $\delta$ (Goldman et al., 1988; Buonanno et al., 1989), unlike the changes in $\alpha-, \beta-$, $\gamma-$, and $\delta$-mRNA, it is not altered by denervation, and it does not appear to be due to muscle activity. We believe a simple explanation for the decrease in $\epsilon$-mRNA after day 15 is related to the observation by Witzemann et al. (1987) and Brenner et al. (1990) that $\epsilon$-mRNA is more abundant in synapse rich zones of adult innervated muscle. If only muscle nuclei near synaptic sites are stimulated under the influence of the nerve to transcribe the $\epsilon$-gene at high rates, then the growth of the endplate free regions of muscle fibers that occurs between day 15 and adulthood (Cardassis and Cooper, 1975) should result in an increasing relative abundance of extrasynaptic nuclei and a resultant decrease in the relative abundance of synaptic mRNA. Therefore, the decrease in the level of $\epsilon$-mRNA after day 15 may be secondary to the important aspect of gene regulation, i.e., what factor(s) determines the differential regulation of genes from synaptic nuclei (Merlie and Sanes, 1985; Fontaine and Changeux, 1989; Goldman and Staple, 1989; Brenner et al., 1990)?

In conclusion, we propose that a minimum of three transcriptional regulatory mechanisms are involved in determining the amount and distribution of AChR in skeletal muscle fibers: (1) Transcription of all five genes is activated as a part of the endogenous program of myogenesis to characteristic constitutive levels determined by the individual gene promoters. (2) Nerve induced muscle activity causes a decrease in the relative transcription rates of $\alpha-, \beta-, \gamma-$, and $\delta$-genes. In the case of $\alpha$-subunit, tissue-specific gene activation and regulation by activity have been shown to be mediated by cis-acting element(s) contained within an 850-bp fragment of the promoter proximal to the transcription start site (Klarsfeld et al., 1987; Wang et al., 1988; Merlie and Kornhauser, 1989). (3) $\alpha$-, $\beta$-, and $\gamma$-subunit mRNAs are detectable in adult innervated fibers and are more abundant 


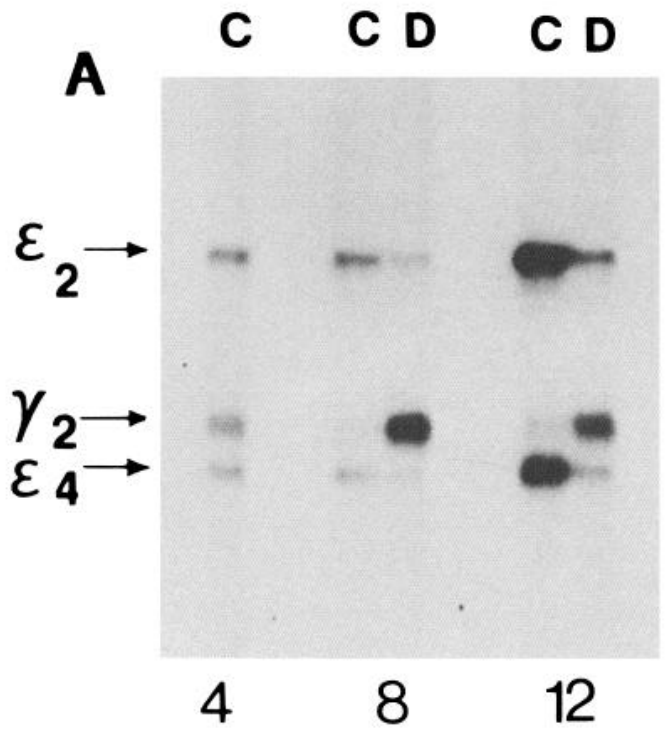

DAYS

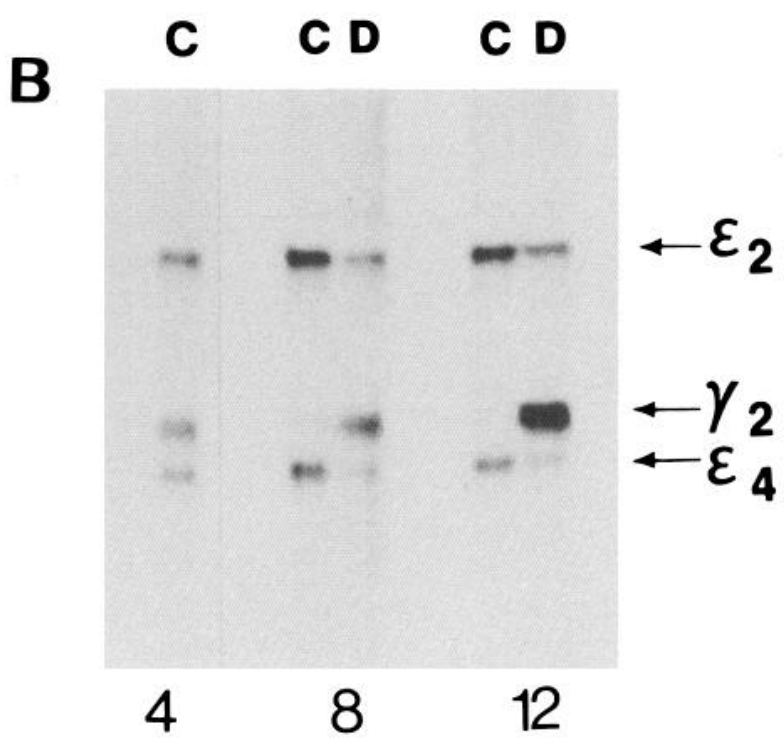

DAYS

Figure 7. Effects of denervation on of $\gamma$ - and $\epsilon$-subunit mRNA in newborn mice. $A$, Newborn mice were denervated unilaterally on day PN4. The gastrocnemius muscle was removed 4 and $8 \mathrm{~d}$ after denervation corresponding respectively to days PN8 and PN12. $B$, The mice were injected daily with thyroxine from day 4 . Each point has been obtained with total RNA from 12-15 mice. This experiment has been repeated three times with consistent results. $C$, control; $D$, denervated.

\section{$\mathcal{E}$ exon $2 \rightarrow$}
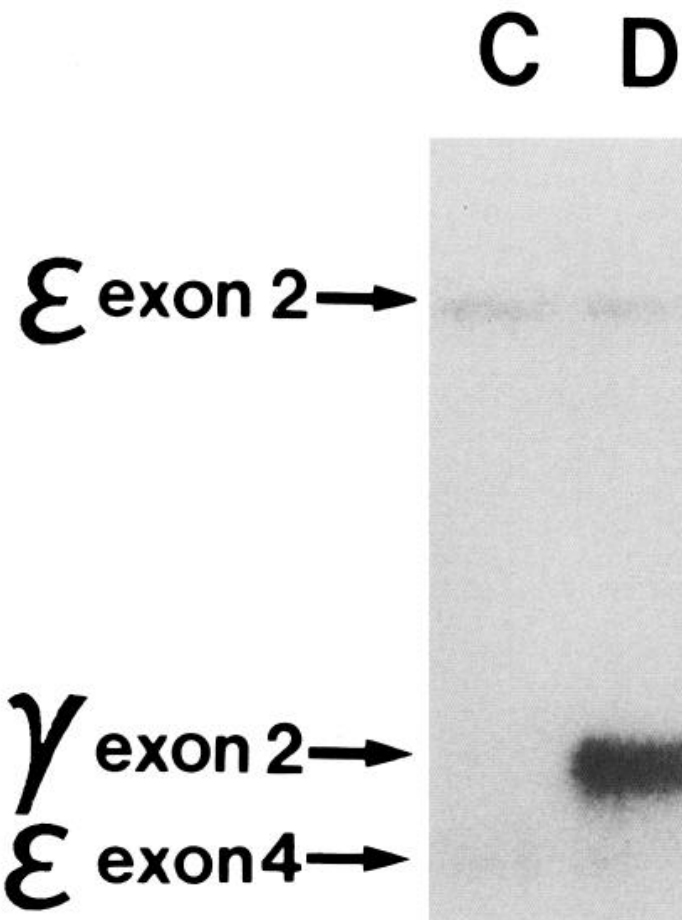
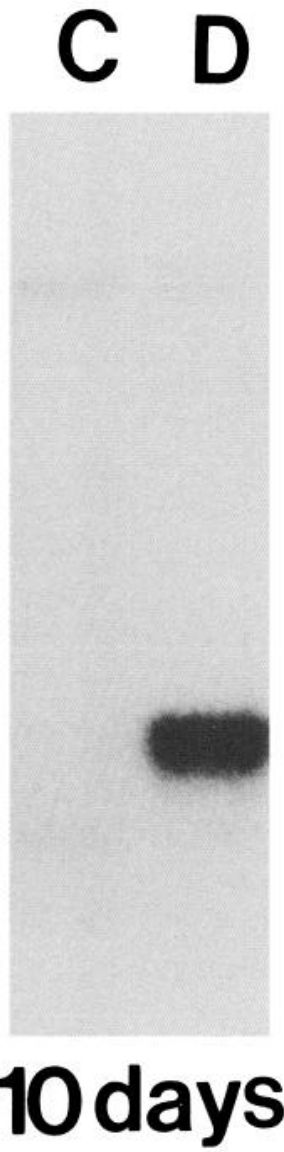

Figure 8. Effects of denervation on $\gamma$ and $\epsilon$-subunit mRNA in adult mice. Adult mice were denervated unilaterally. Both gastrocnemius and soleus muscles were removed together and assayed for $\gamma$ - and $\epsilon$-mRNA levels 4 and $12 \mathrm{~d}$ after denervation. The experiment has been repeated twice. $C$, control; $D$, denervated. 
near synaptic sites (Merlie and Sanes, 1985; Fontaine and Changeux, 1989; Goldman and Staple, 1989). Similar studies have shown that the $\epsilon$-mRNA is concentrated at synaptic sites (Witzemann et al., 1987; Brenner et al., 1990). However, whereas the levels of $\alpha-, \beta-, \gamma-$, and $\delta$-mRNA increase extrasynaptically upon denervation (Fontaine and Changeux, 1989; Goldman and Staple, 1989), the level of $\epsilon$-mRNA is unaffected. We suggest that the regulation of transcription by nerve-evoked activity is mediated by a unique combination of $c i s$ - and trans-acting factors common to only the $\alpha-, \beta-, \gamma-$, and $\delta$-genes. High transcription in synaptic nuclei, on the other hand, is a mechanism shared by all five genes, and one that depends on activity and/or some other trophic influence of the nerve. Thus, for each gene, the levels of mRNA at synaptic and extrasynaptic sites are determined by the balance among the three mechanisms: activity resulting in a negative effect throughout the fiber, the neurotrophic influence resulting in a positive effect in synaptic regions, and both of these are superimposed upon a constitutive level mediated by the tissue-specific elements. The $\epsilon$-gene may provide, therefore, a simple model with which to study the neurotrophic influence on gene transcription in the absence of the antagonistic influence of activity.

\section{References}

Brehm P, Steinbach JH, Kidokoro Y (1982) Channel open time of acetylcholine receptors on Xenopus muscle cells in dissociated cell culture. Dev Biol 91:93-102.

Brehm P, Kidokoro Y, Moody-Corbett F (1984) Acetylcholine receptor channel properties during development of Xenopus muscle cell in culture. J Physiol (Lond) 357:203-217.

Brenner HR (1985) Neurotrophic control of channel gating? Nature 317:572-573.

Brenner HR, Sakmann B (1983) Neurotrophic control of channel properties at neuromuscular synapses of rat muscles. J Physiol (Lond) 337: 159-171.

Brenner HR, Meier TH, Widmer B (1983) Early action of nerve determines motor endplate differentiation in rat muscle. Nature 305: 536-537.

Brenner HR, Lomo T, Williamson R (1987) Control of end-plate channel properties by neurotrophic effects and by muscle activity in rat. J Physiol (Lond) 388:367-381.

Brenner HR, Witzemann V, Sakmann B (1990) Imprinting of acetylcholine receptor messenger RNA accumulation in mammalian neuromuscular synapses. Nature 344:544-547.

Buonanno AB, Casabo L, Kornhauser J, Crowder CM, Merlie JP (1989) Transcriptional regulation of acetylcholine receptor genes in transfected muscle cells and transgenic mice. In: Molecular biology of neuroreceptors and ion channels (Maelicke A, ed), NATO ASI, VH32, pp 541-552. New York: Springer.

Cardassis CA, Cooper GW (1975) An analysis of nuclear numbers in individual muscle fibers during differentiation and growth: a satellite cell-muscle fiber growth unit. J Exp Zool 191:347-358.

Chizzonite RA, Zak R (1984) Regulation of myosin isoenzyme composition in fetal and neonatal rat ventricle by endogeneous thyroid hormones. J Biol Chem 259:12628-12633.

Chomczynski P, Sacchi N (1987) Single-step method of isolation by acid guanidinium thiocyanate-phenol-chloroform extraction. Anal Biochem 162:156-159.

Crowder CM, Merlie JP (1986) DNAse I-hypersensitive sites surround the mouse acetylcholine receptor $\delta$-subunit gene. Proc Natl Acad Sci USA 83:8405-8409.

Fischbach GD, Schuetze SM (1980) A post-natal decrease in acetylcholine channel open time at rat end-plates. J Physiol (Lond) 303: 125-137.

Fontaine B, Changeux JP (1989) Localization of nicotinic acetylcholine receptor $\alpha$-subunit transcripts during myogenesis and motor end plate development in the chick. J Cell Biol 108:1025-1037.

Frail DE, Musil LS, Buonanno A, Merlie JP (1989) Expression of RAPsyn (43K protein) and nicotinic acetylcholine receptor genes is not coordinately regulated in mouse muscle. Neuron 2:1077-1086.
Gambke B, Lyons GE, Halegrove J, Kelly AM, Rubinstein NA (1983) Thyroidal and neural control of myosin transitions during development of rat fast and slow muscles. FEBS Lett 156:335-339.

Goldman D, Staple J (1989) Spatial and temporal expression of acetylcholine receptor RNAs in innervated and denervated rat soleus muscle. Neuron 3:219-228.

Goldman D, Brenner HR, Heinemann S (1988) Acetylcholine receptor $\alpha-, \beta-, \gamma-$, and $\delta$-subunit mRNA levels are regulated by muscle activity Neuron 1:329-333.

Greenberg AS, Nakajima S, Nakajima Y (1985) Functional properties of newly inserted acetylcholine receptors in embryonic Xenopus muscle cells. Dev Brain Res 19:289-296.

Gu Y, Hall ZW (1988) Immunological evidence for a change in subunits of the acetylcholine receptor in developing and denervating rat muscle. Neuron 1:117-125.

Igusa Y, Kidokoro Y (1987) Two types of acetylcholine receptor channels in developing Xenopus muscle cells in culture: further kinetics analyses. J Physiol (Lond) 389:271-300.

Kawa K, Obata K (1982) Altered developmental changes of neuromuscular junction in hypo- and hyperthyroid rats. J Physiol (Lond) 329:143-161.

Klarsfeld A, Daubas P, Bourachot B, Changeux J-P (1987) A 5 '-flanking region of the chicken acetylcholine receptor $\alpha$-subunit gene confers tissue specificity and developmental control of expression in transfected cells. Mol Cell Biol 7:951-955.

Kullberg RW, Brehm P, Steinbach JH (1981) Nonjunctional acetylcholine receptor channel open time decreases during development of Xenopus muscle. Nature 289:411-413.

Kullberg RW, Owens JL, Vickers J (1985) Development of synaptic currents in immobilized muscle of Xenopus laevis. J Physiol (Lond) 364:57-68.

Lassar AB, Paterson BM, Weintraub H (1986) Transfection of a DNA locus that mediates the conversion of $10 \mathrm{~T}^{1} / 2$ fibroblasts to myoblasts. Cell 47:649-656.

Leonard RJ, Nakajima S, Nakajima Y, Takahashi T (1984) Differential development of two classes of acetylcholine receptors in Xenopus muscle in culture. Science 226:55-57.

Leonard RJ, Nakajima S, Nakajima Y, Carlson CG (1988) Early development of two types of nicotinic acetylcholine receptors. J Neurosci 8:4038-4048.

Melton DA, Krieg PA, Rebagliati MR, Maniatis T, Zinn K, Green MR (1984) Efficient in vitro synthesis of biologically active RNA and RNA hybridization probes from plasmids containing a bacteriophage SP6 promoter. Nucl Acids Res 12:7036-7070.

Merlie JP, Kornhauser JM (1989) Neural regulation of gene expression by acetylcholine receptor promoter in muscle of transgenic mice. Neuron 2:1295-1300.

Merlie JP, Sanes JR (1985) Acetylcholine receptor mRNA is concentrated in synaptic regions of adult muscle fibers. Nature 317:66-68.

Michler A, Sakmann B (1980) Receptor stability and channel conversion in the subsynaptic membrane of the developing mammalian neuromuscular junction. Dev Biol 80:1-17.

Mishina M, Takai T, Imoto K, Noda M, Takahashi T, Numa S, Methfessel C, Sakmann B (1986) Molecular distinction between fetal and adult forms of muscle acetylcholine receptor. Nature 321:406-411.

Sakmann B, Brenner HR (1978) Change in synaptic channel gating during neuromuscular development. Nature 276:401-402.

Schubert D, Harris AJ, Devine CE, Heinemann S (1974) Characterization of a unique muscle cell line. J Cell Biol 61:398-413.

Schuetze SM, Vicini S (1984) Neonatal denervation inhibits the normal neonatal decrease in endplate channel open time. J Neurosci 4: 2297-2302.

Schuetze SM, Frank EF, Fischbach GD (1978) Channel open time and metabolic stability of synaptic and extrasynaptic acetylcholine receptors on cultured chick myotubes. Proc Natl Acad Sci USA 75: 520-523.

Siegelbaum SA, Trautmann A, Koenig J (1984) Single acetylcholineactivated channel currents in developing muscle cells. Dev Biol 104: 366-379.

Takai T, Noda M, Mishina M, Shimizu S, Furutani Y, Kayano T, Ikeda T, Kubo T, Takahashi H, Takahashi T, Kuno M, Numa S (1985) Cloning, sequencing and expression of cDNA for a novel subunit of acetylcholine receptor from calf muscle. Nature 315:761-764.

Taylor S, Jones P (1979) Multiple new phenotypes induced in 10T $1 / 2$ and 3T3 cells treated with 5-azacytididne. Cell 17:771-779. 
Wang Y, Xu H-P, Wang X-M, Ballivet M, Schmidt J (1988) A cell type-specific enhancer drives expression of the chick muscle acetylcholine receptor $\alpha$ subunit gene. Neuron 1:527-534.

Witzemann V, Barg B, Nishikawa Y, Sakmann B, Numa S (1987) Differential regulation of muscle acctylcholine receptor $\gamma$ and $\epsilon$-subunit mRNAs. FEBS Lett 223:104-112.
Witzemann V, Barg B, Criado M, Stein E, Sakmann B (1989) Developmental regulation of five subunit specific mRNAs encoding acetylcholine receptor subtypes in rat muscle. FEBS Lett 242:419-424.

Yaffe D, Saxel O (1977) Serial passage and differentiation of myogenic cells isolated from dystrophic mouse muscle. Nature 270:725-727. 